\title{
Apical Ballooning Syndrome (Takotsubo Cardiomyopathy) after Permanent Dual-Chamber Pacemaker Implantation
}

\author{
Armando Gardini, Francesco Fracassi, Emiliano Boldi, and Remo Albiero \\ Department of Cardiology, S. Rocco Hospital, Ome, 25050 Brescia, Italy \\ Correspondence should be addressed to Armando Gardini, armando.gardini@libero.it
}

Received 17 April 2012; Accepted 1 August 2012

Academic Editors: M.-H. Jim, T. Kasai, and F. M. Sarullo

Copyright ( $) 2012$ Armando Gardini et al. This is an open access article distributed under the Creative Commons Attribution License, which permits unrestricted use, distribution, and reproduction in any medium, provided the original work is properly cited.

Apical ballooning syndrome, also called takotsubo cardiomyopathy, has been recently reported. It may mimic acute myocardial infarction and is typically observed in postmenopausal women after stressful events. A 75-year-old female after permanent dual chamber pacemaker implant complained of chest pain with repolarization alterations suggesting acute myocardial ischemia. Echocardiography showed a left ventricle with akinesia of the apical portions and reduced global systolic function. The patient was treated with antithrombotic agents and intravenous nitrates. No coronary lesions were found at angiography. At ventriculography, a typical takotsubo-like shape of the left ventricle was observed. The clinical and echocardiographic picture normalized at discharge.

\section{Introduction}

Apical ballooning syndrome (ABS) has been reported since the 1990s in Japan [1]. The clinical presentation mimics acute myocardial infarction (AMI) and is characterized by chest pain and or dyspnoea, ST segment elevation, mild cardiac enzymes increase, transient left ventricular systolic dysfunction with hypokinesia of the middle and distal portions of the left ventricle (LV) and hyperkinesia of basal segments, and absence of coronary artery lesions. It typically affects postmenopausal women, and the prognosis is usually favourable. An emotional or physical stressful event often precedes the clinical picture [2-4]. We describe a case of ABS which occurred after permanent pacemaker implantation.

\section{Case Report}

A 75-year-old woman with history of hypertension and no previous cardiac symptoms was admitted for syncope and paroxysmal third-degree atrioventricular (AV) block. Preoperative evaluation revealed normal haematological tests, chest X-ray, and echocardiography. The EGC presented first-degree AV block, right bundle branch block, and left anterior fascicular block. A dual-chamber pacemaker (PM) with ventricular lead in the right ventricle (RV) apex was then implanted without procedural complications. On the night following the implant, the patient complained of repeated self-limited episodes of interscapular pain with mild dyspnoea. The day after the ECG showed sinus rhythm triggering PM ventricular stimulation with ST segment elevation in inferior and anterior leads. PM inhibition showed the preexisting intraventricular conduction disturbance with inferior and anterior ST segment elevation (Figure 1). Chest $\mathrm{X}$-ray excluded pneumothorax. At echocardiogram, akinesia of the apical portions of the LV with reduced LV systolic function was observed. Cardiac biomarkers were slightly increased. The patient was treated with intravenous nitrates and antithrombotic agents due to suspicion of AMI. For the persistence of symptoms and ECG alterations, coronary angiography was performed with no evidence of significant coronary lesion or spasm. The ventriculography revealed ballooning of apical region with typical so-called takotsubo shape (Figure 2). In the following days, reduction in ST segment elevation and transient negative $\mathrm{T}$ wave were observed at ECG. At predischarge echocardiography, LV systolic function improved, and wall motion abnormalities 


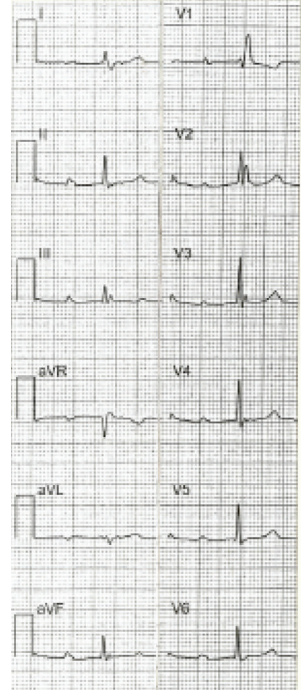

(a)

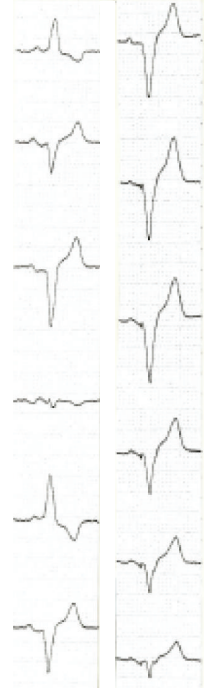

(b)

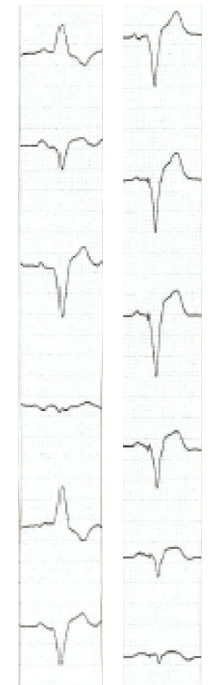

(c)

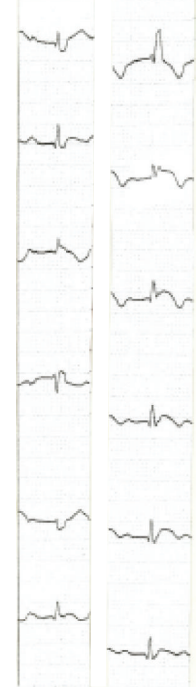

(d)

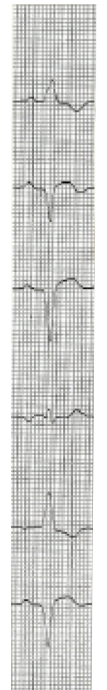

(e)

FIGURE 1: Evolving ECG aspect: (a) spontaneous sinus rhythm with first-degree AV block and right bundle branch block, (b) early postimplant with dual-chamber pacing, (c) dual-chamber pacing with ST segment elevation in inferior and anterior leads, (d) spontaneous rhythm with PM inhibited and ST segment elevation in inferior and anterior leads, and (e) dual-chamber pacing at discharge with evolving repolarization abnormalities.

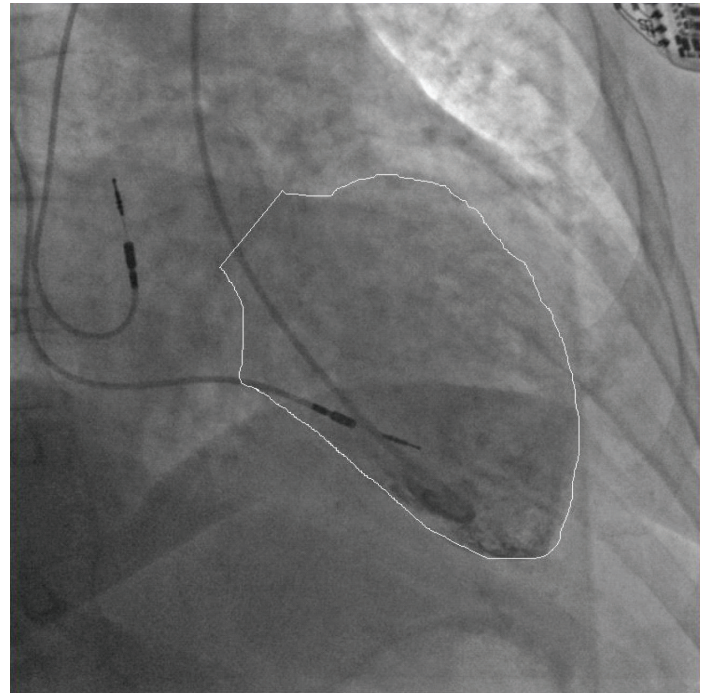

(a)

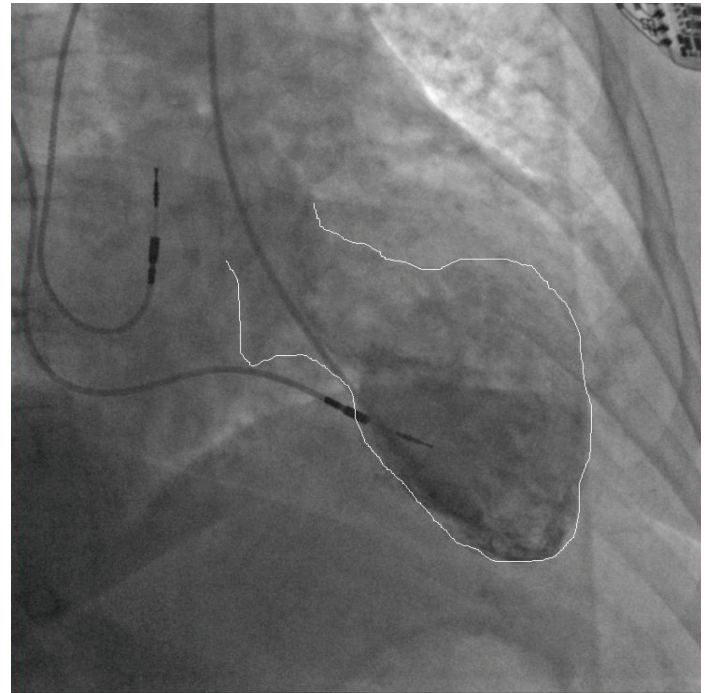

(b)

FIGURE 2: Ventriculography showing typical takotsubo-like shape of LV.

disappeared. The patient was discharged asymptomatic with normal cardiac enzymes, effective dual-chamber stimulation, and normalized systolic LV function.

\section{Discussion}

The ABS is also known as takotsubo cardiomyopathy because the LV shape in the acute phase is very similar to a pot with round bottom and narrow neck used in Japan to trap octopuses $[1,4]$. It is often preceded by emotional or physical stressful events. The underlying mechanism is unclear, but it seems mainly related to an excess of catecholamine release [3]. Pacemaker implantation even if uncomplicated may be sufficiently stressful in individual patients to precipitate this syndrome as previously described in some cases [5-10]. In our patient, as in the previously reported cases, no other perioperative stressful events other than implantation itself were identified that could explain the clinical syndrome, typically characterized by chest pain, ST segment elevation on ECG, transient LV wall motion 
abnormalities with takotsubo-like shape at ventriculography, slight cardiac enzymes increase, and absence of significant coronary lesions, according to current accepted criteria [2, 4]. The most common ECG presentation of ABS is ST segment elevation in precordial leads suggesting anterior wall AMI. Concomitant ST segment elevation or absence of ST segment depression in inferior leads has been proposed as an adjunctive ECG abnormality distinguishing ABS [11]. It is also interesting to note that acute myocardial ischemia may be difficult to identify based on ECG analysis in PM patients paced in the apex of the RV. Several signs were proposed, but they are all insensitive [12]. Marked ST segment elevation in predominantly negative QRS complex was proposed as a distinctive criterion [13], but this abnormality may be observed during classical apical RV pacing also in the absence of acute myocardial ischemia or infarction. Indeed, in symptomatic patients, the diagnosis should be based on new development of ST elevation [12]. In our patient, ST segment elevation in anterior and inferior leads was observed both during spontaneous AV conduction and during apical RV stimulation. The relevance of the latter finding in the diagnosis of ABS during apical RV pacing needs further evaluation. Moreover, a confusing factor inducing transient repolarization modifications in patients with modern dualchamber PM may be the presence of variable AV delay and consequent variable degree of ventricular capture [14]. This may be observed in PM provided with algorithms aimed at prolonging the AV delay searching for spontaneous $\mathrm{AV}$ conduction or, on the contrary, aimed at decreasing the AV delay in response to increasing heart rate.

In conclusion, ABS should be suspected after pacemaker implantation in patients, especially postmenopausal women, presenting with angina-like symptoms and/or dyspnoea, new development of ST modification, and LV systolic dysfunction. The recovery of a preevent ECG aspect and of a normal LV systolic function in the followup may help to confirm the diagnosis.

\section{References}

[1] K. Dote, H. Sato, H. Tateishi, T. Uchida, and M. Ishihara, "Myocardial stunning due to simultaneous multivessel coronary spasms: a review of 5 cases," Journal of Cardiology, vol. 21, no. 2, pp. 203-214, 1991.

[2] A. Prasad, "Apical ballooning syndrome: an important differential diagnosis of acute myocardial infarction," Circulation, vol. 115, no. 5, pp. e56-e59, 2007.

[3] I. S. Wittstein, D. R. Thiemann, J. A. C. Lima et al., "Neurohumoral features of myocardial stunning due to sudden emotional stress," New England Journal of Medicine, vol. 352, no. 6, pp. 539-548, 2005.

[4] M. Gianni, F. Dentali, A. M. Grandi, G. Sumner, R. Hiralal, and E. Lonn, "Apical ballooning syndrome or takotsubo cardiomyopathy: a systematic review," European Heart Journal, vol. 27, no. 13, pp. 1523-1529, 2006.

[5] S. Kurisu, I. Inoue, T. Kawagoe et al., "Persistent left ventricular dysfunction in takotsubo cardiomyopathy after pacemaker implantation," Circulation Journal, vol. 70, no. 5, pp. 641-644, 2006.
[6] K. Kimura, Y. Tanabe-Hayashi, S. Noma, and K. Fukuda, "Rapid formation of left ventricular giant thrombus with Takotsubo cardiomyopathy," Circulation, vol. 115, no. 23, pp. e620-e621, 2007.

[7] S. G. Chun, V. Kwok, D. K. Pang, and T. K. Lau, "Transient left ventricular apical ballooning syndrome (takotsubo cardiomyopathy) as a complication of permanent pacemaker implantation," International Journal of Cardiology, vol. 117, no. 1, pp. e27-e30, 2007.

[8] R. A. H. Abu Sham'a, E. Asher, D. Luria, M. Berger, and M. Glikson, "Apical ballooning syndrome: a complication of dual chamber pacemaker implantation," Indian Pacing and Electrophysiology Journal, vol. 9, no. 4, pp. 229-232, 2009.

[9] R. F. Kohnen and L. H. B. Baur, "A Dutch case of a takotsubo cardiomyopathy after pacemaker implantation," Netherlands Heart Journal, vol. 17, pp. 487-490, 2009.

[10] P. G. Golzio, M. Anselmino, D. Presutti, E. Cerrato, M. Bollati, and F. Gaita, "Takotsubo cardiomyopathy as a complication of pacemaker implantation," Journal of Cardiovascular Medicine, vol. 12, no. 10, pp. 754-760, 2011.

[11] M. H. Jim, A. O. O. Chan, P. T. Tsui et al., "A new ECG criterion to identify takotsubo cardiomyopathy from anterior myocardial infarction: role of inferior leads," Heart and Vessels, vol. 24, no. 2, pp. 124-130, 2009.

[12] S. S. Barold and B. Herweg, "Electrocardiographic diagnosis of myocardial infarction and ischemia during right ventricular pacing," Journal of Electrocardiology, vol. 40, no. 2, pp. 164167, 2007.

[13] E. B. Sgarbossa, "Recent advances in the electrocardiographic diagnosis of myocardial infarction: left bundle branch block and pacing," Pacing and Clinical Electrophysiology, vol. 19, no. 9, pp. 1370-1379, 1996.

[14] M. O. Sweeney, "Minimizing right ventricular pacing: a new paradigm for cardiac pacing in sinus node dysfunction," American Heart Journal, vol. 153, no. 4, pp. S34-S43, 2007. 


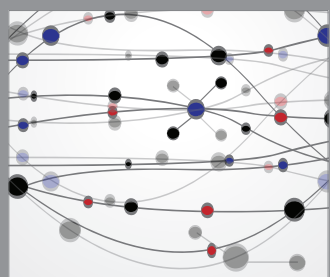

The Scientific World Journal
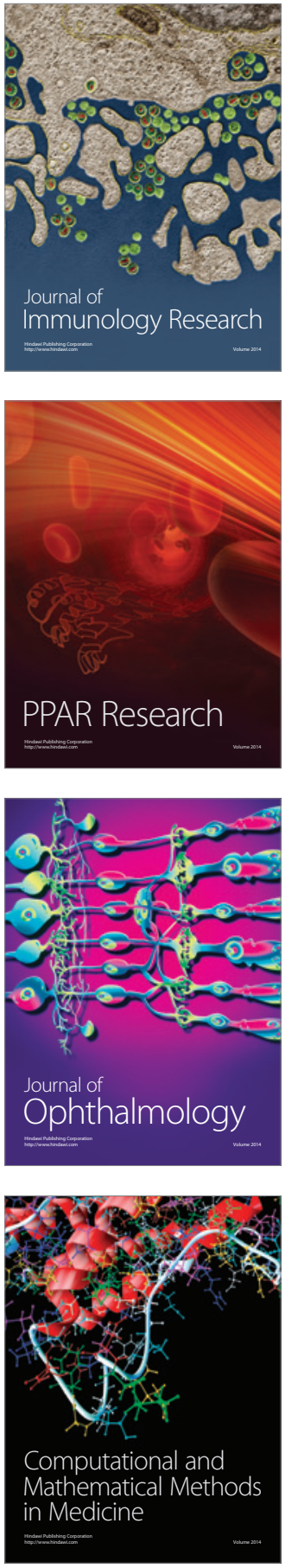

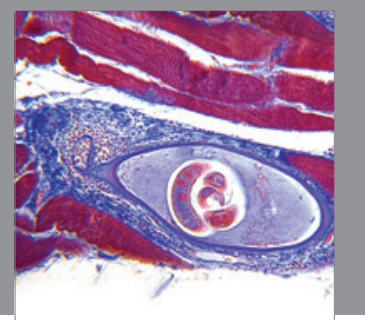

Gastroenterology

Research and Practice
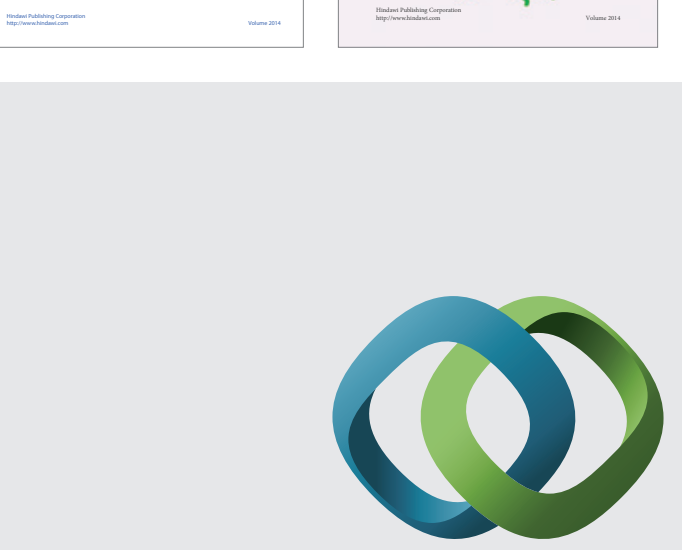

\section{Hindawi}

Submit your manuscripts at

http://www.hindawi.com
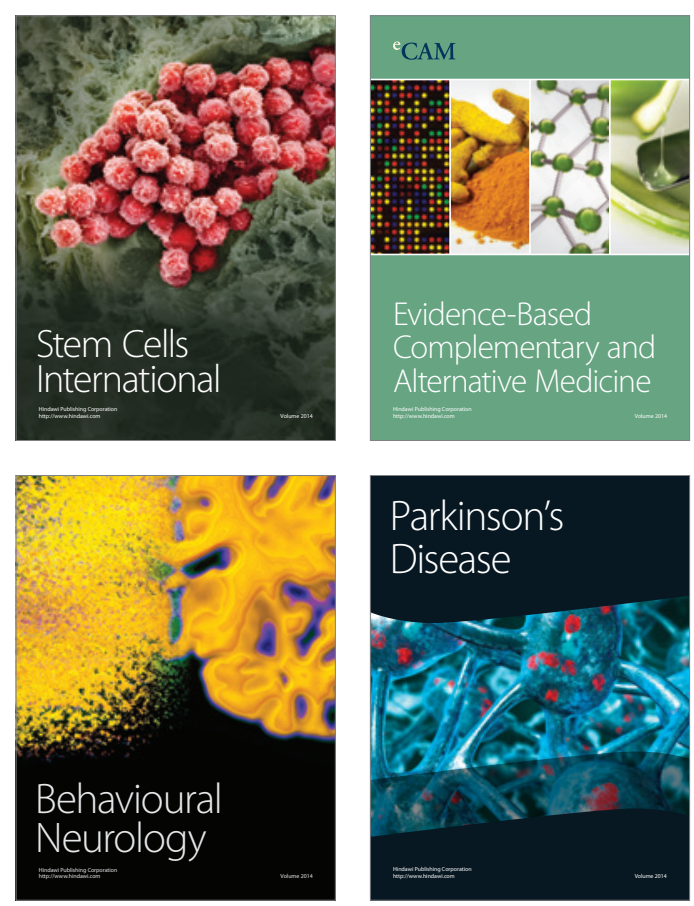

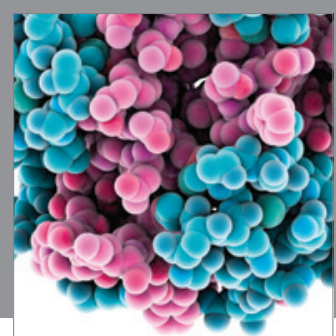

Journal of
Diabetes Research

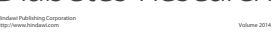

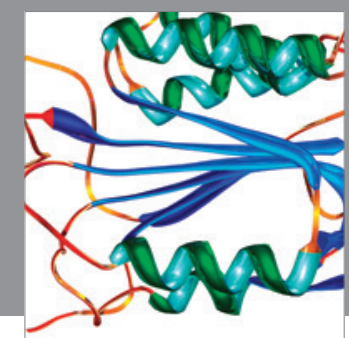

Disease Markers
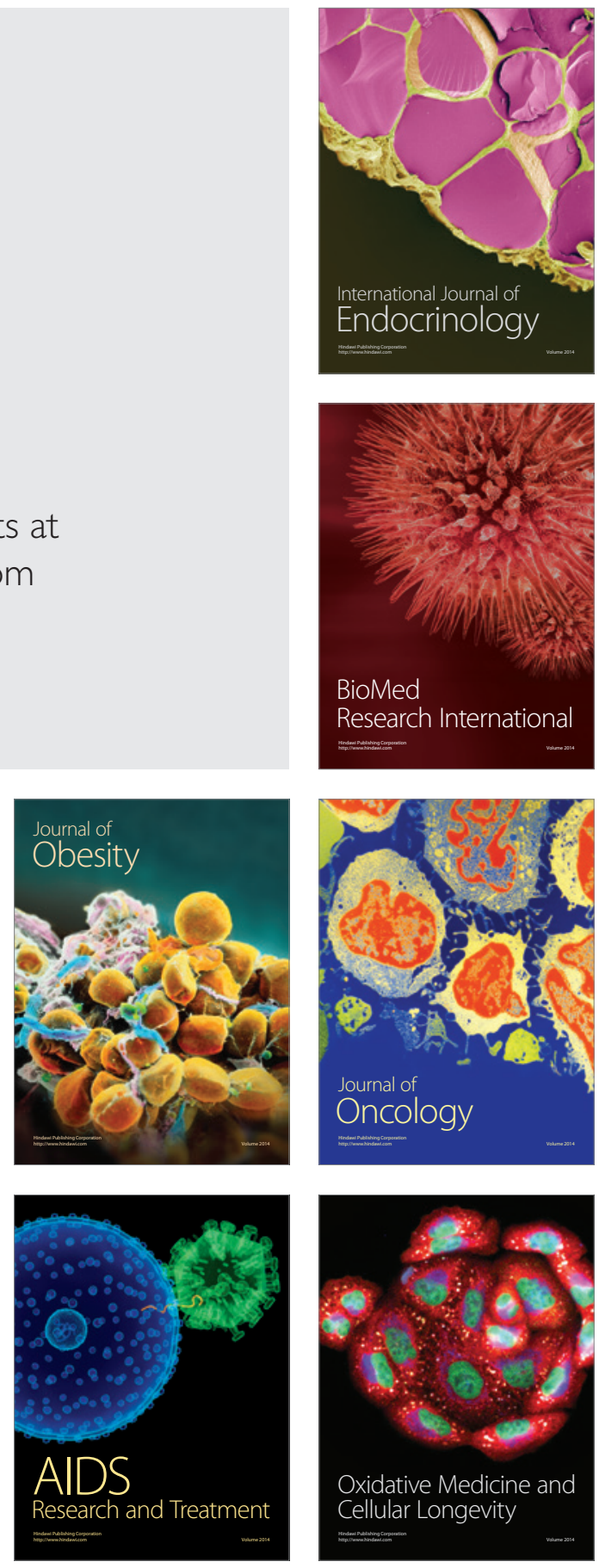